An endowment of US $\$ 8$ millions or Sw.Frs 12 millions would suffice for this and meanwhile satisfy other of the above needs from income.

(i) Sponsorship without financial commitment of appropriate conferences such as the projected series of International Conferences on Waste Minimization and Clean Technology.

Further projects are under consideration, including urgent research proposals, a major World Heritage Series of volumes, establishment of a biennial award for demonstrated environmental concern and concomitant action by a multinational corporation, and fostering the establishment of associated foundations etc. in other parts of the world.* With the demise of the Pahlavi Prize, the modest value by modern standards of its successor the International Sasakawa Environment Prize, and the opening of the Tyler Prize to wider concerns, a major award for environmental leadership is an urgent need-if possible on a par with the Nobel Peace Prize (for which, incidentally, the nomination of leading environmentalists seems particularly desirable).

\section{OPERATION AND NEEDS}

With the running costs already largely accounted for, and in the absence of any institutional overheads and taxes other than those that continue to be paid privately, the Foundation constitutes what has been called a uniquely economical vehicle for support of the environmental/conservational movement-whether generally or through specific projects which can be put in train as soon as or soon after funds become available. Contributions are warmly welcomed and individually acknowledged, and can be received in any negotiable currency by cheque made out to the Foundation for Environmental Conservation, c/o $\mathrm{Mr}$ Heinz Christen, Pictet \& Cie Banquiers, 29 Boulevard Georges-Favon, 1204 Geneva, Switzerland, or sent to the Foundation's address ending this notice. [Plans for recognizing special services or substantial donations to the Foundation by the award of an engraved certificate designed by a renowned draughtsman have been shelved with the death of the draughtsman and in view of the urgent need of all available funds for more pressing purposes, though donors are requested to identify themselves clearly unless anonymity is desired.]

\author{
Nicholas Polunin, President \\ The Foundation for Environmental Conservation \\ (updated version following its 14th Annual General \\ Meeting, held on 28 February 1989). \\ Address: 7 Chemin Taverney \\ 1218 Grand-Saconnex \\ Geneva, Switzerland.
}

* These include the International Vernadsky Foundation. established in 1988 and centred on the USSR. of which the President is one of the 10 Founders, and an International Centre for Biosphere Studies, which has recently been recommended. inter alia at our urging, to be located in the Institute of Soil Science and Photosynthesis in Pushchino. USSR. They also include the (Indian) National Environmental Conservation Association, of which the President is a life Member and a Member of the Advisory Board. and the collaborating International Society of Naturalists (INSONA), of which the President is an elected Fellow and Patron.

\title{
The Need for a World Conservation Archive
}

In a few years' time, through the courtesy of the Swiss authorities. IUCN hopes to move to a new headquarters building. The design of an appropriate building is now being considered, and this note proposes that, within it, a World Conservation Archive should be established.

\section{Why a Conservation Archive is Important}

When the history of the late 20th century comes to be written, it seems very probable that one of the features which will strike the historian most forcibly is the mounting recognition of human impact on the natural world, and the need to conserve and manage its renewable resources if humanity is to have a future. The growth of conservation activities from the 1940s onwards, led by pioneers of long experience and mounting concern and marked in 1948 by the creation of IUPN (the International Union for Protection of Nature), later to become IUCN, will stand out as one of the landmarks on this historical pathway.

Historians will want to analyse just what happened, why, and how the key actors in the drama behaved. They will not be satisfied with the generalizations in the published sources, and will want to go back to original records of meetings, correspondence, diaries, and the like. This can only be done effectively if such unique material is safeguarded for future scholarly scrutiny, and a specialist conservation archive is surely the answer to such a need.

\section{Location of an Archive}

The right place for such an archive is obviously in the new headquarters of IUCN - the World Conservation Union. IUCN itself has already a wealth of such documents pertinent to the history of this period, and there are many people still alive who played a central part in the early years of establishment of IUPN and IUCN and who would willingly deposit their material with the new archive if it was established and supervised under proper, modern conditions, with the curation of the material thereby guaranteed. Steps need to be taken urgently to reassure such individuals that this will be done.

There are a number of specialized archives in other fields. They are much sought after by scholars. For example, the history of research into the exploration of the polar regions is particularly based on studies of such archives as that at the Scott Polar Research Institute in Cambridge, England, UK, where proper air-conditioned facilities permit the safe keeping of unique manuscripts from the age of Antarctic exploration around the turn of the century and the earlier periods of Arctic discovery over 150 years ago. When once a good archive is established, it tends to attract material and progressively increase its value to scholars.

\section{The Design of an Archive}

It is proposed that special, air-conditioned facilities be designed in the new IUCN headquarters, on the advice of a professional curator of such material. The room or rooms concerned would need to be located alongside, and curated in association with, the IUCN library. This in itself needs to be planned and endowed as a unique collection of conservation literature, much of it donated by well-wishers to IUCN over the years. A World Conservation Library alongside a World Conservation Archive would be of immense value to visiting scholars, who would also benefit from day-to-day contact with the staff of the World Conservation Union. 
Such a facility would need to be endowed or sponsored, to guarantee its continuity. IUCN has very limited endowment, and depends for its financial balance on year-to-year fund-raising. This is not a satisfactory arrangement for a long-term facility such as the one discussed in this memorandum. Accordingly, it is suggested that the creation of a World Conservation Archive and a World Conservation Library should be the subject of bequest, donation, or sponsorship, by a patron or patrons whose names (or the names of those who they might prefer to see associated) would of course be attached to the facility.

MARTIN W. HoldGATE, Director General
IUCN/UICN
Avenue du Mont-Blanc
I196 Gland
Switzerland.

\section{Garbage Dump in the Marshall Islands?}

Far away, in the central-western Pacific Ocean, is a tiny and little-known, but remarkable and indeed unique, island. It is an uninhabited coral atoll, called in Marshallese 'Pokak' or 'Bokak' (on charts it is marked 'Taongi') (Fig. 1). It is the northernmost island of the vast Marshall Archipelago (Fig. 2), and is about 14 by 4 miles ( 22.5 by $6.4 \mathrm{~km}$ ) in dimensions, crescent-shaped, with a reef broken only by one narrow outlet from a rather shallow lagoon with many patch-reefs. On the southeastern curve of the outer reef of the crescent are a string of dry islets, with sparse but interesting vegetation, including one almost-endemic grass species. It is the only known coral atoll where the sea, driven by the trade-winds, pours in over the windward reef, and flows out in one narrow channel through the reef, maintaining a constant level in the lagoon.

The most spectacular feature, however, is the presence, on these islets, of what may be the largest sea-bird 'rookery' in the world. When the birds are frightened and fly up, they blacken the sky - millions of birds! Vast numbers of sooty and a half-dozen other species of terns nest there; sandflats are honeycombed and riddled with burrows of wedgetailed and Christmas-Island shearwaters, tropic-birds, three species of boobies, piratical frigate-birds that pursue

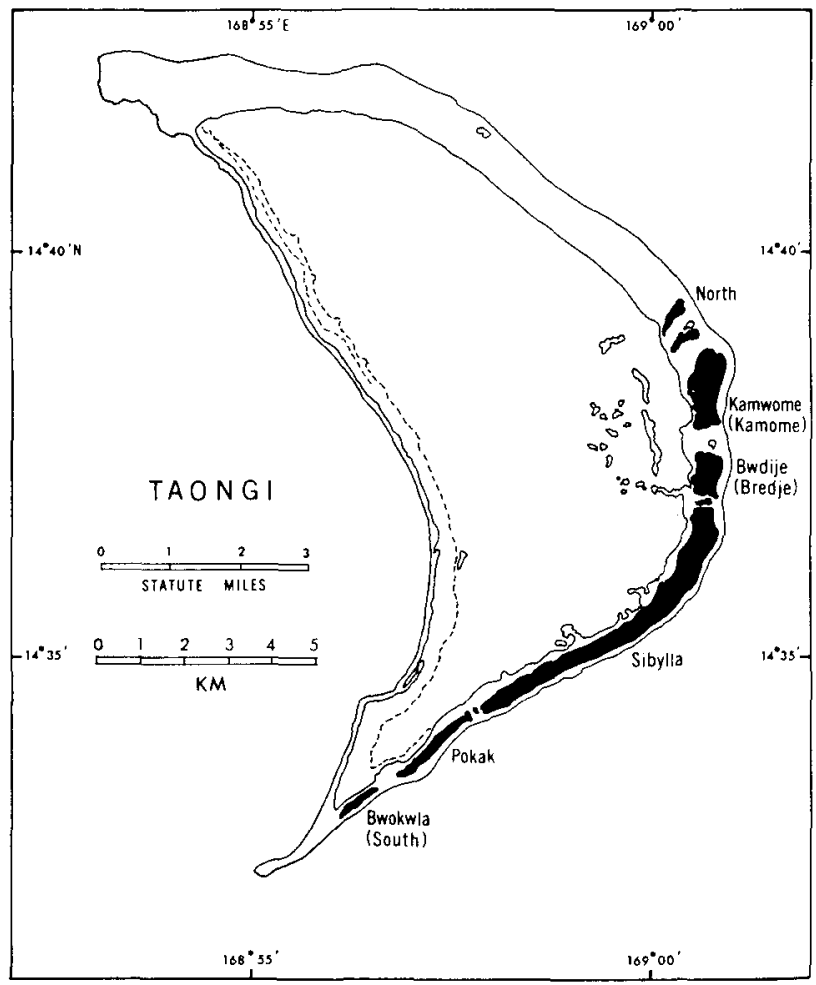

FIG. 1. Map of Taongi.

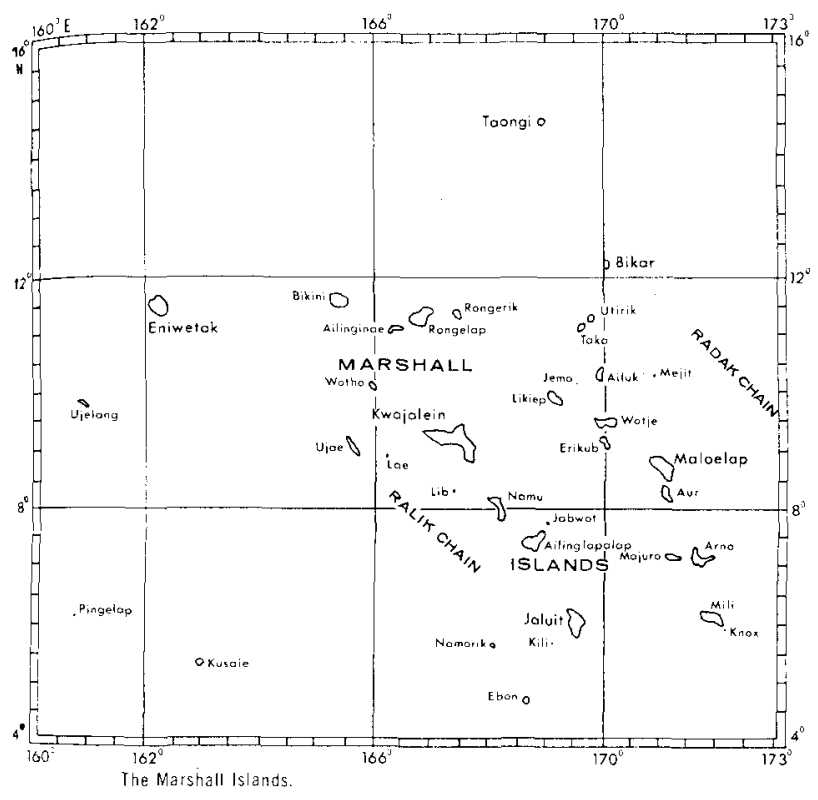

Fig. 2. Map of the Marshall Islands.

the boobies and steal their fish-all share these tiny pieces of land as well as the fishes of the lagoon and the waters around the island. In addition there are reef-herons, curlews, turnstones, golden plovers, wandering tattlers, and other shorebirds, migrants from north and south. Albatrosses have been seen in the vicinity.

Many smaller land-animals, insects, crustaceans, and spiders, abound. In addition to the land animals and vegetation, there are rich marine fauna and flora. Many species of corals and coralline Algae have built spectacular reefs, inhabitated by myriads of beautiful reef-fishes, molluscs, and crustacea.

This is a wondrous natural world, almost unchanged by Man. Its remoteness, small land-area, and total lack of fresh water, have protected it. The Marshallese people are said to have regarded this atoll, and Bikar the next one lying to the south and likewise uninhabited by humans, in preEuropean times as sacred areas - sanctuaries for birds and sea-turtles. This status was made legal in a decree issued by the American District Administrator of the US Trust Territory of the Pacific. It has been a hope that this regulation would be continued and made law by the government of the new Republic of the Marshall Islands - which has given strong indications of a far-sighted wish to preserve, to the extent that proves practical, the biological diversity of these islands, and has had a survey team in the field to determine how best this can be done.

Such being the case, it was a great and disagreeable shock to see, in a local newspaper, the Marshall Islands Journal, 